It is desirable that the titration of both the entrance and exit samples be made in the same direction, usually from acid to alkali, to minimize as far as possible the personal error of the analyst in judging endpoints under the varied conditions of lighting during the $24 \mathrm{hrs}$.

\section{COMPUTATIONS ${ }^{1}$}

A representative calculation is as follows: Entranch Samples

Bulb Number 1 Butb Number 2

\begin{tabular}{|c|c|c|}
\hline $\begin{array}{l}\text { Weight of bulb"andsample } \ldots \ldots \ldots \ldots \\
\text { Weight of bulb. } \ldots \ldots \ldots \ldots \ldots \ldots \ldots \ldots\end{array}$ & $\begin{array}{l}63.1600 \mathrm{~g} \\
62.5025\end{array}$ & $\begin{array}{l}69.0565 \mathrm{~g} . \\
68.4605 \mathrm{~g}\end{array}$ \\
\hline $\begin{array}{l}\text { Weight of sample } \ldots \ldots \ldots \ldots \ldots \\
\text { Standard acid used } \ldots \ldots \ldots \ldots \ldots\end{array}$ & $\begin{array}{l}0.6575 \mathrm{~g} \\
21.05 \mathrm{cc} . \\
21.05 \times 0.0014\end{array}$ & $\begin{array}{c}0.5960 \mathrm{~g} \\
18.95 \mathrm{cc} . \\
18.95 \times 0.0014\end{array}$ \\
\hline Per cent combined nitrogen. & $\frac{21.05 \times 0.0014}{0.6575}$ & 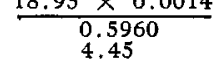 \\
\hline Exit $S$ & $\begin{array}{l}\text { AMPLES } \\
\text { Bulb Number } 3\end{array}$ & Bulb Number 4 \\
\hline $\begin{array}{l}\text { Weight of bulb:and sample....... } \\
\text { Weight of bulb.................. }\end{array}$ & $\begin{array}{l}75.0775 \mathrm{~g} \\
74.4865\end{array}$ & $\begin{array}{l}67.6830 \mathrm{~g} \\
67.0580\end{array}$ \\
\hline $\begin{array}{l}\text { Weight of sample............... } \\
\text { Standard alkali used............. }\end{array}$ & $\overline{0.5910} \mathrm{~g}$ & $\begin{array}{c}0.6250 \\
18.30 \mathrm{cc}\end{array}$ \\
\hline Per cent combined nitros & $\begin{array}{c}\frac{17.23 \times 0.0014}{0.5910} \\
4.08\end{array}$ & $\frac{18.30 \times 0.0014}{0.6250}$ \\
\hline
\end{tabular}

Efficiency of conversion $=\frac{4.09}{4.47}=91.6$ per cent

1 Slide rule used for all computations.

\section{VARIATIONS IN PROCEDURE}

The procedure described above can be varied by the absorption of the entrance sample in an acid solution and the absorption of the exit sample in an alkaline solution. While this, perhaps, is more correct in theory, experience shows that absorption in water, if the manipulation is carefully done, gives practically the same results, and is somewhat simpler. Also, a neutralized hydrogen peroxide solution may be introduced, instead of oxygen, into the exit sample, but by so doing the end-point may be somewhat obscured, and it is believed that the use of oxygen is preferable. In fact when running on mixtures comparatively low in ammonia, the addition of any oxidizing agent is apparently unnecessary, additional air being drawn into the bulb instead of either oxygen or peroxide.

\section{PRECISION OF METHOD}

There is a very slight error introduced in this method by the dilution of the sample with the air drawn from the sample tube into the bulb ahead of the sample. This is so small, however, as to be negligible. Other sources of error which can be practically eliminated by care in manipulation are condensation in the sample tube when taking the exit gases, leakage in to the converter itself around the $e_{+}$ges of the sample hole because of the suddenly applied vacuum, thus giving a false sample, changes in temperature, barometric pressure, and moisture conditions between the successive weighings of the same bulb and incomplete absorption of the gases in the bulb.

Also any small amount of ammonia passing the catalyzer unoxidized, together with an equivalent amount of oxidized ammonia, is not determined in the titration of the exit gas sample, but this amount is usually well within the probable error of the method, and hence can be neglected. If desired, however, an estimation of this ammonia can be made by colorimetric methods, and the results modified accordingly.
It is also to be noted that an efficiency determination by this method will be correct even if the two standard solutions are "off," provided they have been checked against each other, which is normally done once on every shift.

The fact remains, however, that the effect of all these possible sources of error is slight, and the efficiencies obtained by this method appear to be as precise as those obtained by any of the other methods, the average precision of a single efficiency determination in duplicate being, it is believed, within about plus or minus $3 / 4$ per cent.

\section{COMPARISON WITH OTHER METHODS}

The chief merit of the "bulb" method is its simplicity, both in the analytical work and in the calculations, a decided advantage in practical plant control. It has been found that two plant chemists using this method can average for an 8-hour shift one efficiency determination an hour, run in duplicate, which is considerably oftener than determinations can be made by two men using any of the volumetric methods. This saving in time is important as it is believed that for a thorough study of converter operation a large number of tests taken as frequently as possible is very desirable. In fact, a succession of instantaneous samples seem to give better and more reliable operating data than a continuous sample taken over the same period.

For plant operation, however, the ideal method would be one that would give a continuous record in chart form of the instantaneous efficiencies, as a check on the operating force. There are possibilities along this line, but, in the meantime, it is believed that the "bulb" method is the most satisfactory of the methods yet described for practical plant use.

\section{USE OF METHOD}

This method was devised by the writer in I9I6, for use in the experimental ammonia oxidation plant of the American Cyanamid Company, at Warners, New Jersey. It was used at that plant for all experimental work, and was later used for plant control and testing at U. S. Nitrate Plant No. 2, Muscle Shoals, Alabama, and was used with slight modifications at U. S. Nitrate Plant No. I, Sheffield, Alabama, and at the experiment station connected therewith. WAR DERARTMENT

OfFICE OF THE ChIEF OF ORDNANCE Nitrate Division WASHINGTON, D. C.

\section{THE CUPROUS CHLORIDE-IODINE METHOD FOR REDUCING SUGARS SIMPIIFIED}

$$
\text { By F. M. ScALES }
$$

Received January 29, 1919

About three years ago, in the course of an investigation for converting cellulose into dextrose, the author found it necessary to work out a volumetric method for determining the amount of cuprous oxide precipitated in the Soxhlet solution recommended by Munson and Walker. This solution was employed because it gave the most satisfactory results in the presence of the salts in the sugar solution. A new method was 
fourd for determining cuprous oxide by dissolving it with hydrochloric acid, adding in excess a known quantity of iodine, to react with the cuprous chloride formed, and then titrating the excess iodine with sodium thiosulfate. A report of the work was published at the time. ${ }^{1}$ Two years later Cammidge ${ }^{2}$ published a modification of the method that appeared to be satisfactory except that he retained the undesirable procedure that I had found necessary, $i$. e., transferring the hot cuprous chloride solution from one flask to another. He found that if Benedict's solution was used the acidification with hydrochloric acid produced sufficient carbon dioxide to prevent the oxidation of the cuprous chloride by the air. This discovery afforded a means for greatly simplifying the procedure. Clark ${ }^{3}$ has taken full advantage of this discovery by carrying out the whole process in one flask. The latter author has done much work to show the accuracy of the method but unfortunately his procedure does not give him a thiosulfate-dextrose ratio that is constant within the limits that he has taken for the method. It is for the purpose of setting forth the possible improvements in procedure that the present report is written.

When the Benedict's solution containing the sugar has been boiled and the cuprous oxide has been precipitated, the solution may be acidified with a dilute acetic acid which does not attack the cuprous oxide, a known excess of iodine may be added, and the cuprous oxide then dissolved by the addition of a very small quantity of hydrochloric acid. The cuprous chloride formed is immediately acted on by the iodine with the formation of cuprous iodide and finally cupric iodide. The presence of the cuprous iodide is not evident in this method as it is in the others, for the solution never has any cloudiness or precipitate. As soon as the cuprous oxide is all dissolved by the hydrochloric acid the excess of iodine is titrated with the thiosulfate, starch solution being used as the indicator. The difference between the thiosulfate value of the iodine added in a determination and the thiosulfate required to reduce the iodine after the formation of cupric iodide is equivalent to the amount of reducing sugar present. The value of the iodine in cc. of thiosulfate must be determined by titration in distilled water and not in the presence of the reagents employed in a determination. In a test with all the reagents, but no sugar present, 0.3 or $0.4 \mathrm{cc}$. of iodine is reduced to hydriodic acid and so the results are low by this amount, but in a regular determination all this iodine unites with the copper so that the full iodine value is obtained.

This method for sugar determination may be carried out in one flask without the thistle tube and pipettes which Clark's method requires. It does not necessitate the precautions against oxidation by the air nor the care that he had to exercise in measuring the iodine from a pipette since the iodine may be

1 "The Determination of Reducing Sugars," J. Biol. Chem., 23, 81.

2 "An Improved Method for the Estimations of Sugar in the Urine and Blood," Lancet, 192 (1917), 613.

"Volumetric Determination of Reducing Sugars," J. Am. Chem. Soc., 40, 1759 rapidly run into the solution from a burette without great care concerning the exact quantity, although the amount used must be carefully read at the end of the titration with thiosulfate before making any calculations.

\section{METHOD}

REAGENTS-The Benedict's solution ${ }^{1}$ employed is the one recommended by Clark. In addition to this the method requires an approximately $0.04 \mathrm{~N}$ iodine solution; a thiosulfate solution ${ }^{2}$ made approximately $0.04 N$; hydrochloric acid solution diluted so that every 25 cc. contains I. $5 \mathrm{cc}$. of the concentrated acid (I.Ig sp. gr.); an acetic acid solution containing $2.4 \mathrm{cc}$. of the glacial acid in every Ioo cc.; and a starch solution made in the usual way with either potato or soluble starch. A pure dextrose ${ }^{3}$ solution should be employed to standardize the apparatus and thiosulfate solution.

APPARATUs-The solutions were boiled in a $300 \mathrm{cc}$. Erlenmeyer flask with a 2 -hole rubber stopper. A smaller flask will serve as well. In addition to this there is required a $100 \mathrm{cc}$. cylinder or any container for approximately this quantity, a $25 \mathrm{cc}$. pipette, and two burettes, or, if one prefers to deliver the iodine from a pipette, a ro cc. and a $25 \mathrm{cc}$. pipette may be substituted for one of the burettes. If pipettes are used, one of $5 \mathrm{cc}$. will be convenient where the reduction to cuprous oxide is so slight that the solution shows practically no clouding or precipitate; the ro cc. pipette may be employed where very small quantities of the oxide settle to the bottom of the flask; and the larger pipette for all larger quantities of the precipitate. All the data given in this report were obtained by measuring the iodine from a burette.

PROCEDURE-The procedure for making a determination consists in pouring $20 \mathrm{cc}$. of the modified Benedict's solution into a $300 \mathrm{cc}$. Erlenmeyer flask and then making the volume up to $30 \mathrm{cc}$. with the sugar solution and distilled water if necessary. If there are present more than $20 \mathrm{mg}$. of dextrose better results may be obtained by using $25 \mathrm{cc}$. of Benedict's solution and making the volume up to $35 \mathrm{cc}$. with the sugar solution. The flask is then placed over a flame or on a hot plate. When using the electric hot plate to heat the solution, the flask should be closed with a

1 Modified Benedict's solution:

Copper sulfate crystals........... $16.0 \mathrm{~g}$.

Sodium citrate ................. $150.0 \mathrm{~g}$.

Sodium carbonate, anhyd.......... 130.0 g.

Sodium bicarbonate............... $10.0 \mathrm{~g}$

Water to make a final volume of 1 liter.

The copper may be dissolved separately in 125 to $150 \mathrm{cc}$. of water; the remaining solid constituents in about $650 \mathrm{cc}$. of water, heating to accelerate solution. When all are in solution pour the copper solution slowly into the other with stirring, make tip nearly to volume, cool, complete the volume to 1 liter, and filter.

None of the weighings or measurements need to be made with extreme accuracy.

2 The thiosulfate solution was made by dissolving $10 \mathrm{~g}$. of the pure salt in 1 liter of water. Its sugar equivalent should be determined by making some regular sugar determinations with pure dextiose. The solution used in this work was standardized against $N / 20$ potassium bichromate, $15 \mathrm{cc}$. of the latter equalling $18.6 \mathrm{cc}$. of thiosulfate; an exactly $0.04 \mathrm{~N}$ solution would have required $18.75 \mathrm{cc}$. A fresh solution was used in this work, but the strength during the first two weeks, when most of the change takes place, could be determined more easily with potassium bichromate than by making a regular sugar determination.

- A pure dextrose for this purpose may be obtained from the Bureau of Standards. 
2-hole rubber stopper in order to bring the solution to the boiling point quickly. The hot plate employed in this work, required about $5 \mathrm{~min}$. to bring the solution to boiling. When the total volume was $35 \mathrm{cc}$. it required one and three-quarter minutes longer to boil. As Clark has shown in his work, when a burner is used to heat the solution it should be adjusted so that the total time of heating will be about one minute less than that allowed for the plate. The period of heating and the intensity of the heat must be constant for all determinations. The boiling was continued for 3 min. The solution was then cooled as quickly as possible, usually in a minute, by holding the flask under the cold water faucet and rotating it. When cold, the Ioo cc. of dilute acetic acid may be poured into the solution and the iodine immediately run in from a burette. The dilute hydrochloric acid is then run in from a $25 \mathrm{cc}$. pipette which is held against the side of the flask up near the neck, so that the acid will spread over the side of the flask as it runs down; the solution is vigorously rotated to produce an immediate distribution of the acid and thus prevent any concentration of it that might act on the iodine. The pipette and the side of the flask are washed down with a few cubic centimeters of water and the solution rotated for exactly one minute. Any precipitate should be entirely dissolved in this time. The thiosulfate solution is now carefully run into the flask till its brown or blue solution changes to a light sea green, when $2 \mathrm{cc}$. of starch solution may be added and the titration continued until the dark iodo-starch blue suddenly fades away and the solution remains the light blue characteristic of acidified copper solutions. The end point obtained is permanent.

\section{DATA}

The accuracy of the method was tested with varying quantities of pure dextrose. The solutions were prepared by dissolving $0.75 \mathrm{~g}$. of dextrose in $250 \mathrm{cc}$. of distilled water.

The restults obtained with duplicate samples are shown in Table I.

\begin{tabular}{|c|c|c|c|c|c|c|}
\hline \multirow{4}{*}{$\begin{array}{l}\text { Dextrose } \\
\text { Present } \\
\text { Mg. } \\
0.0\end{array}$} & \multirow{4}{*}{$\begin{array}{c}\text { Todine } \\
\text { Added } \\
\text { Cc. } \\
10.0 \\
10.0 \\
1.0\end{array}$} & \multirow{4}{*}{$\begin{array}{c}\text { Equiv- } \\
\text { alent to } \\
\text { Iodine } \\
\text { Cc. } \\
9.78 \\
9.83 \\
0.981\end{array}$} & \multirow{3}{*}{$\begin{array}{l}\text { Required } \\
\text { in } \\
\text { Determi- } \\
\text { nations } \\
\text { Cc. }\end{array}$} & THIOSULFATE- & \multirow{3}{*}{$\begin{array}{l}\text { Aver- } \\
\text { age } \\
\text { Cc. }\end{array}$} & \multirow{3}{*}{$\begin{array}{c}\text { Dextrose } \\
\text { Value } \\
\text { per Cc. } \\
\text { Mg. }\end{array}$} \\
\hline & & & & \multirow{2}{*}{$\begin{array}{l}\text { Difference be } \\
\text { tween Iodine } \\
\text { Equivalent } \\
\text { and De- } \\
\text { and De- } \\
\text { Cc. } \\
\text { C. }\end{array}$} & & \\
\hline & & & & & & \\
\hline & & & & $\ldots \ldots$ & $\ldots$ & $\ldots$ \\
\hline 1.5 & 6.0 & $\begin{array}{r}5.89 \\
5.89\end{array}$ & $\begin{array}{l}4.57 \\
4.61\end{array}$ & 1.32 & 130 & 115 \\
\hline 3.0 & 6.0 & 5.89 & 3.23 & 2.6 & & \\
\hline 3.0 & 5 & 5.59 & 2.9 & 2.63 & 2.65 & 1.13 \\
\hline 4.5 & 10.00 & 9.81 & 5.73 & 4.08 & & \\
\hline $\begin{array}{l}4.5 \\
6.0\end{array}$ & & & & & 4.06 & 1,11 \\
\hline 6.0 & & & 4.3 & & 5.43 & 1.11 \\
\hline $\begin{array}{l}9.0 \\
9.0\end{array}$ & $\begin{array}{l}19.99 \\
19.80\end{array}$ & $\begin{array}{l}19.61 \\
19.42\end{array}$ & $\begin{array}{l}11.59 \\
11.42\end{array}$ & $\begin{array}{l}8.02 \\
8.00\end{array}$ & 8.01 & 1.12 \\
\hline 12.0 & 19.58 & 19.21 & 8.54 & 10.67 & & \\
\hline 12.0 & 19.62 & 19.25 & 8.52 & 10.73 & 10.70 & 1.12 \\
\hline 15.0 & 21.96 & 21.54 & 8.19 & 13.35 & & \\
\hline 15.0 & & & & & 13.36 & 1.12 \\
\hline $\begin{array}{l}24.0 \\
24.0\end{array}$ & $\begin{array}{l}24.97 \\
25.00\end{array}$ & $\begin{array}{l}24.50 \\
24.53\end{array}$ & $\begin{array}{l}3.00 \\
3.00\end{array}$ & $\begin{array}{l}21.50 \\
21.53\end{array}$ & 21.52 & 1.12 \\
\hline
\end{tabular}

The figures in the last column of the table show that the method is very accurate and they are so nearly the same value that any error arising from taking I.I $2 \mathrm{mg}$. of dextrose as the constant value of the thiosulfate, under these conditions, would easily fall within the limits of experimental error.

A total heating period of $8 \mathrm{~min}$. was used in all the determinations except the one where $24 \mathrm{mg}$. of dextrose were present, in which case it required $9^{3 / 4} \mathrm{~min}$. in order to allow a 3 -min. boiling period. More time was necessary for the latter determinations, partly because of the larger volume of solution employed, but principally because of a fluctuation in the source of heat. Fluctuations in heat gave considerable trouble. The influence of drafts around the flask was overcome by placing an asbestos cylinder 7 in. high and 6 in. in diameter on the hot plate. This arrangement helped some, but could not of course offset fluctuations in the temperature of the hot plate as the following figures show:

\begin{tabular}{|c|c|c|c|c|}
\hline & Time Required & TABLE II & Thiosulfate & Dextrose \\
\hline $\begin{array}{l}\text { Dextrose } \\
\text { Present } \\
\text { Mg. }\end{array}$ & $\begin{array}{l}\text { to Keach } \\
\text { Boiling Point } \\
\text { Min. }\end{array}$ & $\begin{array}{l}\text { Boiled } \\
\text { Min. }\end{array}$ & $\begin{array}{l}\text { Equivalent to } \\
\text { Dextrose } \\
\text { Ce. }\end{array}$ & $\begin{array}{c}\text { Thiosulfate } \\
\text { Mg. }\end{array}$ \\
\hline 1.5 & 4.0 & 3.0 & 1.35 & 1.11 \\
\hline 1.5 & 4.0 & 3.0 & 1.37 & 1.10 \\
\hline 15.0 & 4.75 & 2.25 & $\begin{array}{l}13.14 \\
13.33\end{array}$ & 1.14 \\
\hline $\begin{array}{l}15.0 \\
15.0\end{array}$ & $\begin{array}{l}4.0 \\
4.0\end{array}$ & $\begin{array}{l}3.0 \\
3.0\end{array}$ & $\begin{array}{l}13.33 \\
13.28\end{array}$ & $\begin{array}{l}1.13 \\
1.13\end{array}$ \\
\hline 1.5 & 4,0 & 3.0 & 1.36 & 1.10 \\
\hline
\end{tabular}

The reagents used for this test were the same as those employed for the determinations given in Table $\mathrm{I}$. These determinations, however, were made 3 days later and the total heating period, due to the presence of the asbestos cylinder, was one minute less.

In these determinations it will be noted that when I $5 \mathrm{mg}$. of dextrose are employed the value of I cc. of thiosulfate is equal to I.I $3 \mathrm{mg}$. of dextrose or within $0.01 \mathrm{mg}$. of the value obtained in Table I. When r.5 $\mathrm{mg}$. are used the dextrose value of cc. of thiosulfate varies from that obtained with the larger quantity of dextrose by $0.03 \mathrm{mg}$. just as it did in Table I. In the latter case, however, the value per cubic centimeter is less with the smaller quantity of dextrose, while in Table I it was greater by $0.03 \mathrm{mg}$. The variation in the quantity of dextrose obtained is very slight if the true value of the thiosulfate is taken as that obtained with the I $5 \mathrm{mg}$. of dextrose.

It is best to have an excess of iodine present equivalent to from 5 to $8 \mathrm{cc}$. of the approximately $0.04 \mathrm{~N}$ thiosulfate solution. Determinations were made with I.5 mg. of dextrose using iodine equivalent to 6.00 cc. and I0.00 cc. of thiosulfate; the results were the same. Fifteen milligrams of dextrose with iodine equivalent to $19.00 \mathrm{cc}$. and $24.00 \mathrm{cc}$. also gave the same results.

Clark's ${ }^{1}$ results gave a gradually decreasing dextrose value per cubic centimeter of thiosulfate, as larger quantities of sugar were used in a determination. A total difference of $0.12 \mathrm{mg}$. per cc. of thiosulfate exists between the value obtained with I.O mg. and that with $25.0 \mathrm{mg}$. of dextrose. In the present method the only change from a constant value occurs with I.5 mg. of dextrose and here the difference from the other values is so slight, $0.03 \mathrm{mg}$., that no error is introduced by

${ }^{1}$ Loc. cit. 
ignoring it. Although the author did not obtain the same figure with the smallest quantity of dextrose as he did with the larger ones; it is interesting to note that the average of the results with I.5 mg. of dextrose in Tables $I$ and II gives the value taken as the correct constant per cubic centimeter of thiosulfate.

Various modifications can be made in this method, such as adding the acetic acid, then the hydrochloric acid, and finally running in a known excess of iodine and titrating back with thiosulfate. Under carefully controlled conditions good duplicate results can be obtained in this way, but the dextrose-thiosulfate value is not constant.

While the method described may be modified, as outlined by Clark, and used for much larger quantities of sugar than those employed in the present work, still very accurate results may be obtained by diluting the sugar solution so that it will come somewhere near the limit employed in this investigation.

The same procedure may be used for reducing sugars other than dextrose.

\section{SUMMARY}

A method is described for the determination of reduced copper by iodimetry in a modified Benedict's solution.

The method is simpler than any previously reported. The ratio of reducing sugar to thiosulfate is constant. The results of duplicate determinations differ by less than o. I mg. of dextrose.

The method may be used for any reducing sugars.

BUREAU OF PlaNt INdUStry

DEPARTMEITI OF AGRTCULTURE WASHINGTON, D. C.

\section{THE ANALYSIS OF ALLOYS OF TIN}

\author{
By Archibard Craig \\ Received August 15, 1918
}

Though the gravimetric method for tin has been largely superceded by volumetric methods, the analyst occasionally finds the older method of advantage, as, for instance, when the sample is. very small. A discussion of the conditions of greatest accuracy of the analysis based on the nitric acid separation will therefore be of interest to some.

When an alloy of tin is treated with nitric acid, the precipitation is never complete, no matter what the precautions, and the precipitate is always impure. The elements which may be found with the tin in ordinary alloys are antimony, arsenic, phosphorus, copper, iron and magnesium. If sulfur is present in the alloy the treatment with strong nitric acid will cause the formation of lead sulfate, which may be avoided, if it is known in time, by the use of dilute acid. Sulfur will then separate without precipitating lead, and may be burned off without causing error. Lead is not held by tin to an appreciable extent, even in solders, though it may be found in the precipitate if not enough acid is used in washing to prevent hydrolysis. Coarse drillings of bronze are not easily decomposed, and may retain some of the original alloy. This difficulty may be overcome by boiling the strong nitric acid toward the end of the reaction, so that the lumps are broken $u p$ and the acid can reach all of the alloy.

As most varieties of brass and bronze contain the same elements, differing, from the analytical point of view, mainly in the proportions of tin and zinc, the schemes for analysis differ only in the quantities used for the determination of those elements. In the bronze group as large a sample is taken as the tin determination will permit, and for brass, copper is the limiting element, the solution being fnally divided to obtain a suitable quantity of zinc for titration. After the methods of decomposing the different varieties have been disposed of, therefore, the scheme of analysis is the same for all, until the zinc determination is reached.

The ignited tin precipitate should weigh less than $0.5 \mathrm{~g}$. The copper content may be $2 \mathrm{~g}$. or more. Samples often contain copper and lead segregations so marked that it is necessary to sample the sawings or drillings with great care, using the entire fraction delivered by the sampler instead of an even weight, or to sift the entire sample and use proportionate parts of fine and coarse. Mixed drillings may be sampled down to from Io $\mathrm{g}$. to $20 \mathrm{~g}$, treated with nitric acid and filtered, the precipitate ignited and weighed, and an aliquot taken to correspond to the fraction of the solution taken with the pipette.

For ordinary bronze, sample about $3 \mathrm{~g}$. and weigh into a $250 \mathrm{cc}$. beaker, add cautiously $20 \mathrm{cc}$. nitric acid (r.4 sp. gr.), and after violent action has ceased, boil gently until the alloy is entirely decomposed. This is easily seen by observing the disappearance of froth on removing from the hot plate. The residue should be fine and dense. Dilute to $5^{\circ} \mathrm{cc}$. with hot water, stir well, warm half an hour, and filter.

White bronze, which is high in tin, is run on $0.5 \mathrm{~g}$. using $5 \mathrm{cc}$. nitric acid (I.4 sp. gr.) and diluting to 75 to I00 cc. before filtering.

If sulfur is known to be present, treat $3 \mathrm{~g}$. of the sample with $40 \mathrm{cc}$. nitric acid ( $1.2 \mathrm{sp}$. gr.) on the water bath, crushing the lumps if necessary to assist the decomposition and separation.

Brass may be run on as much as $5 \mathrm{~g}$. if special attention is to be paid to small percentages of impurities. It should be treated with slightly dilute acid and not boiled. Generally tin, if present, has a tendency to run through, and evaporation to dryness before filtering may make a better separation; but as some tin goes through the filter in any case, and is recovered afterward, the writer does not consider that evaporation is ever worth while, except in the case of the nitric acid residues of large samples, which may clog the filter unless previously dried.

Select a funnel with a narrow stem and without internal enlargements, particularly near the top, so that the column will not break from below, and air bubbles accidentally forming will be carried down. Fold a $9 \mathrm{~cm}$. filter at a little wider angle than that of the funnel, but not so wide as to form wrinkles at the top. Tear off the corner (single) of the paper which comes next to the glass. Set in this way the filter 